\title{
Redemptive-Historical Approach: Suatu Pendekatan Hermeneutis Injili yang Kristosentris
}

\author{
Fitri Yuliana* \\ *Penulis adalah mahasiswa pascasarjana di Program Studi Magister Teologi di \\ Sekolah Tinggi Teologi SAAT Malang. \\ Email: fitriyuliana51@yahoo.co.id
}

\begin{abstract}
Abstrak: Di satu sisi, penekanan modernisme pada rasionalitas dan historisitas telah menghasilkan kristologi yang kritis-objektif. Di sisi lain, pascamodernisme yang berepistemologi pluralis menghasilkan kristologi yang subjektif. Menanggapi dan menjembatani dua sisi persoalan ini, pendekatan hermeneutis redemptive-historical diajukan sebagai pendekatan alternatif injili. Pendekatan yang berpusat pada Kristus sebagai kulminasi sejarah penebusan (seperti yang disaksikan Alkitab) ini mengaitkan tiga horizon yaitu: textual, epochal, dan canonical untuk menginterpretasikan teks Kitab Suci secara holistik. Pendekatan ini menganalisis sintaksis, konteks sastra, konteks sejarah dan genre-nya (textual horizon), mengaitkannya dengan sejarah penebusan (epochal horizon), dan melihatnya dalam terang keutuhan kanon (canonical horizon). Penggabungan ketiga unsur tersebut menekankan dinamika pemenuhan janji Allah dalam kulminasi tersebut. Dengan demikian, pendekatan hermeneutis redemptive historical dapat mengarahkan orang Kristen pembacaan dan penafsiran Alkitab yang kristosentris.
\end{abstract}

Kata-kata kunci: Pendekatan Redemptive-Historical, Epistemologi, Kristologi Modern Kristologi Pascamodern, Hermeneutika Injili Kristosentris

Abstract: On the one hand, the emphasis of modernism on rationality and historicity has produced a critical-objective Christology. On the other hand, post-modernism with a pluralist epistemology produces subjective Christology. Responding to, and bridging the two sides of this problem, the redemptive-historical hermeneutical approach is proposed as an alternative evangelical approach. The Christ-centered approach as the culmination of the history of redemption (as witnessed to in the Bible) links three horizons, namely: textual, epochal, and canonical to interpret the text of the Scriptures holistically. This approach analyzes syntax, literary context, historical context and its genre (textual horizon), links it to the history of redemption (epochal horizon), and sees it in the light of the canon (canonical horizon). The combination of these three elements emphasizes the dynamic fulfillment of God's promises. Thus, the historical redemptive hermeneutical approach can lead Christians to read and interpret the Christocentric Bible.

Keywords: Redemptive-Historical Approach, Epistemology, Modernist Christology, Post-modernist Christology, Christ-centered Evangelical Hermeneutics 


\section{Pendahuluan}

Modernisme yang sarat dengan rasionalisme dan idealisme turut mewarnai kekristenan. Hal ini tampak jelas dari lahirnya berbagai pendekatan hermeneutis modern yang lebih mengedepankan rasionalitas dan historisitas dalam mencari kebenaran. Dalam era ini kebenaran seolah-olah bergantung pada serangkaian pembuktian empirik karena yang menjadi dasar kebenaran adalah rasio manusia yang terwujud nyata dalam ilmu pengetahuan. ${ }^{1}$ Kondisi ini sangat memengaruhi berbagai doktrin yang diajarkan dalam kekristenan yang salah satunya adalah kristologi. Kristologi yang lahir dari zaman ini bersifat kritis dan analitis di mana fokusnya ada pada historisitas Yesus yang dipertanyakan.

Berbeda dengan modernisme, pascamodernisme justru mengusung semangat perlawanan terhadap beberapa keyakinan modernisme. Kebenaran absolut dan universal yang digadang-gadang oleh era modern justru dijungkirbalikkan di era ini. Pascamodernisme menggaungkan filosofi relativitas. Segala sesuatu tidak mempunyai nilai mutlak karena semuanya bergantung pada sudut pandang sang subjek sehingga kebenaran adalah soal perspektif semata. ${ }^{2}$ Berkaitan dengan kristologi, era ini menuntut adanya keterbukaan pikiran terhadap eksklusivitas kekristenan dan menggantinya dengan inklusivisme dan pluralisme. Satu kebutuhan zaman pascamodern terhadap sosok Kristus adalah relasi yang bersifat personal dan imanen. Kristus yang sesuai dengan selera subjek. Karena itu, kristologi dalam pandangan pascamodern lebih bersifat subjektif.

Untuk menanggapi dan menjembatani dua pandangan yang berbeda ini, penulis ingin mengajukan pendekatan redemptive-historical approach, sebagai sebuah pendekatan hermeneutis alternatif. Pendekatan ini mencoba menafsirkan Alkitab sesuai dengan susunan

${ }^{1}$ Peter Drilling, Premodern Faith in a Postmodern Culture (New York: Rowman \& Littlefield, 2006), 6.

${ }^{2}$ Stephen J. Wellum, God the Son Incarnate: The Doctrine of Christ (Wheaton: Crossway, 2016), 71. yang sudah disajikan oleh Alkitab sendiri. Pendekatan ini akan mengaitkan tiga horison sekaligus: textual, epochal, dan canonical dalam menginterpretasikan teks Kitab Suci. Dalam membaca teks Alkitab, pendekatan ini tidak hanya menganalisis sintaksis, konteks sastra, konteks sejarah dan genre-nya saja (textual horizon) tetapi juga dengan sejarah penebusan (epochal horizon), dan melihatnya dalam terang keseluruhan kanon (canonical horizon). Dengan penggabungan ketiga unsur tersebut, dinamika pemenuhan janji Allah dapat menjadi motif yang tepat dalam pembacaan teks-teks Alkitab yang Christ-centered, di mana janji itu mencapai pemenuhan yang total, final dan sempurna di dalam diri Yesus Kristus.

\section{Persoalan Epistemologi dan Kristologi Modern dan Pascamodern}

\section{Epistemologi dan Kristologi Modern}

Filosofi René Descartes dan Immanuel Kant merupakan akar dari keseluruhan filosofi modern yang mengusung rasionalisme dan idealisme. ${ }^{3}$ Pandangan modern ini menjadikan manusia sebagai pusat realitas yang ada dan realitas merupakan ekspresi dari apa yang ada di dalam pikiran manusia. Dengan demikian, dunia pikiran atau ide mendapatkan tempat yang sangat besar dalam era ini. Tataran ide di era ini memboyong metode keraguan yang digunakan untuk menemukan kebenaran absolut. Jika kebenaran absolut tersebut ditemukan maka pandangan modern mengasumsikan tidak akan ada keraguan lagi di dalamnya. Pandangan ini diperkuat dengan berkembangnya ilmu pengetahuan dan berbagai penemuan di eranya sehingga memungkinkan metode ini untuk dilakukan. Secara singkat, ini merupakan era perkembangan berbagai macam bidang kehidupan, seperti yang Drilling deskripsikan: The freedom of human subject, the importance of the subject in knowing, the magnificence of human creativity, a political order respectful of the intelligence and responsibility of its citizen-these

${ }^{3}$ Drilling, Premodern Faith in a Postmodern Culture, 6. 
are worthy constitutive factors of modernity." ${ }^{4}$ Dalam era modern, kebebasan, pengetahuan, dan kreativitas manusia diperhitungkan sebagai hal-hal yang sangat dihargai dan inilah nilai dari zaman ini.

Implikasinya, pandangan manusia terhadap otoritas Alkitab pun mengalami perubahan drastis. Ada revolusi epistemologis dalam era ini di mana orang tidak begitu saja percaya kepada kebenaran Alkitab. Reliabilitas Kitab Suci mulai dipertanyakan dengan tingkat kecurigaan yang tinggi dan dibenturkan dengan rasionalitas yang diagungkan pada masa modern ini. Pada masa ini lahir kritisisme biblika yang dipelopori oleh Hermann Reimarus dan Gotthold Lessing yang mengusung dua pernyataan serius. Mereka menyatakan bahwa Injil harus diperlakukan seperti dokumen sejarah biasa dan tidak ada unsur inspirasi ilahi di dalamnya bahkan juga tidak dapat dipercaya begitu saja. Selain itu, dalam mendekati teks, mereka mengusulkan agar harus ada kecurigaan yang selalu berasumsi bahwa untuk mempelajari apa yang terjadi, seseorang harus melihat dengan jeli dan mendalam melalui teks yang ada tanpa mengambil nilai-nilai di permukaan. ${ }^{5}$

Nilai yang paling menonjol dalam pandangan modern adalah bahwa kepercayaan seseorang dapat diverifikasi secara ilmiah dengan menghadirkan serentetan bukti yang dapat diandalkan. Menurut Vanhoozer, di era ini metode dinilai lebih penting daripada esensi dan epistemologi lebih berharga daripada metafisika. ${ }^{6}$ Wellum juga mengatakan hal yang senada:

In the modern era, philosophy took a decisive "turn to the subject." Rooted in classical foundationalism, human reason sought to operate apart from divine revelation, with the goal of achieving a universal, unified explanation of all reality. Modernism believed that if human reason simply followed the

${ }^{4}$ Ibid., 7.

${ }^{5}$ Wellum, God the Son Incarnate, 55-56.

${ }^{6}$ Kevin J. Vanhoozer, Is There a Meaning in This Text?: The Bible, the Reader and the Morality of Literary Knowledge (Grand Rapids: Zondervan, 1998), 26-27. correct methods, starting in human autonomy, reason could arive at a grand theory or "metanarrative."

Menurut pengamatan Lewis, pendekatan kritis di era modern telah menghasilkan dua pandangan yang mereduksi pengenalan manusia tentang Allah. ${ }^{8}$ Pertama, pendekatan kritis menimbulkan a great divorce: suatu perpisahan yang sangat menyakitkan antara akademi dan gereja; antara intelektual dan devosional dalam pembacaan Alkitab; antara akal budi dan iman. Pemisahan hal-hal ini terjadi karena hanya kalangan akademisi dan kaum intelektual yang mempunyai perangkat modern untuk melakukan pendekatan kritis terhadap teks Alkitab. Kedua, pendekatan kritis modernisme terhadap Alkitab hanya menghasilkan pengetahuan dan bukan pengalaman iman. Pendekatan kritis modern hanya menyajikan data-data empiris sehingga yang menjadi titik berat modernisme ada pada ranah kognitif saja, sementara itu aplikasi pengetahuan iman tidak dijadikan perhatian yang utama.

Konsep keselamatan injili yang mengakui Yesus sebagai Kristus (Mesias) telah menjadi batu sandungan bagi pandangan modern. ${ }^{9}$ Keberatan utama pandangan modernisme adalah berkaitan dengan hal-hal mesianis (ketuhanan) yang bersifat adi-alamiah yang ada dalam diri dan karya Yesus Kristus, seperti yang disinyalir oleh Vos:

One of the most significant developments in modern discussin of the life and teaching of Jesus is the growing disfavor into which the messianic element in the Gospels has fallen with a certain class of writers . . . the question whether or not Jesus was the Messiah

${ }^{7}$ Wellum, God the Son Incarnate, 69.

${ }^{8}$ C.S. Lewis, God in the Dock: Essay on Theology and Ethics, ed. Walter Hooper (Grand Rapids: Eerdmans, 1977), 213.

${ }^{9}$ Geerhardus Vos, Redemptive History and Biblical Interpretation, ed. Richard B. Gaffin Jr. (Phillipsburg: P\&R, 2001), 330. 
has meaning only within the limits of a strict biblical supernaturalism. ${ }^{10}$

Di sini, tampak bahwa bagi para sarjana biblika modern, sifat adi-alamiah Yesus Kristus bukan sesuatu yang masuk akal. Karena itu, pandangan modern yang bersifat kritis dan empiris dalam mencari kebenaran, menolak unsur atau sifat ini.

Meskipun era modern sudah berlalu pendekatan-pendekatan kritis ala era modern masih digunakan untuk mempertanyakan keabsahan Alkitab. Ini terbukti dari munculnya pandangan Yesus Seminar yang bergantung pada metode-metode ilmiah untuk merekonstruksi dan memisahkan antara Yesus yang sesungguhnya dengan Yesus yang diceritakan dalam kesaksian para murid dalam Alkitab. ${ }^{11}$ Ini dapat dilihat dalam pandangan Lessing yang mempertanyakan nilai epistemis dari historitas Yesus. khususnya mengenai kelahiran-Nya dari seorang perawan; mukjizat-mukjizat yang dibuat-Nya; kematian dan kebangkitan-Nya; dan kedatangan-Nya yang kedua kali. ${ }^{12}$

Singkatnya, segala sesuatu yang berkaitan dengan Tuhan masih bisa diterima di era ini dengan catatan bahwa Tuhan dapat dipahami secara rasional. ${ }^{13}$ Rasio menjadi tolok ukur utama dalam kehidupan beragama bahkan dalam iman. Iman kepercayaan terhadap suatu agama (termasuk kepada Allah) tidak diterima begitu saja seperti pada era pramodern. Secara konseptual, Allah dapat dipandang sebagai Sang Pencipta dan Penopang dunia, namun keterkaitan Tuhan dalam realitas kehidupan manusia sangat minim. Hal ini disebabkan pandangan antroposentris di era ini yang menganggap bahwa hegemoni 324.

${ }^{10}$ Vos, Redemptive History and Biblical Interpretation,

${ }^{11}$ Kevin J. Vanhoozer, First Theology: God, Scripture and Hermeneutics (Downers Grove: IVP Academic, 2002), 17. 56.

${ }^{12}$ Seperti dikutip oleh Wellum, God the Son Incarnate,

${ }^{13}$ Drilling, Premodern Faith in a Postmodern Culture, 8. roda kehidupan berada di tangan manusia yang sudah sangat maju di berbagai bidang. ${ }^{14}$

Perkembangan ilmu pengetahuan yang demikian telah melahirkan penelitian yang kritis terhadap Yesus secara historis yang kemudian memengaruhi formulasi kristologis. Haight menggarisbawahi empat pengaruh penelitian yang mungkin muncul sebagai konsekuensi logis dari penelitian tentang Yesus. ${ }^{15}$ Pertama, akan ada ketegangan yang timbul antara rekonstruksi historis Yesus dengan aspek doktrinal dan transenden dari Kristologi. Kedua, penelitian historis yang mencoba untuk merekonstruksi figur Yesus sudah mempunyai titik awal dan struktur untuk menghubungkan kemanusiaan dan keilahian Yesus. Hal ini berarti bahwa pada perkembangannya, pengakuan akan keilahian Yesus pun faktanya akan bergantung pada hasil penelitian Yesus secara historis. Ketiga, penelitian tentang Yesus berfungsi sebagai norma negatif dalam membentuk kristologi yang integral. Yang dimaksudkan dengan negatif di sini adalah bahwa kita tidak dapat memperkokoh identitas Yesus berdasarkan apa yang tidak ditemukan dalam penelitian sejarah. Keempat, penelitian tentang Yesus menyediakan petunjuk positif untuk menafsirkan kristologi. Kesimpulannya, formulasi kristologis dipaksa untuk menyesuaikan diri dengan penemuanpenemuan empiris yang ada sehingga kristologi yang lahir harus bersifat objektif.

\section{Epistemologi dan Kristologi Pascamodern}

Era pascamodern ditandai dengan penolakan terhadap tatanan dunia modern dan nilainilai yang terkandung di dalamnya seperti rasionalisme dan objektivisme. ${ }^{16}$ Harvey, dalam The Condition of Postmodernity, mendefinisikan pascamodernitas sebagai sebuah reaksi yang menentang "positivist, technocentric, dan rationalistic, universal modernisme, di mana keempat hal ini ditandai dengan adanya

\footnotetext{
${ }^{14}$ Ibid.

${ }^{15}$ Roger Haight, The Future of Christology (New York: Continuum, 2005), 29-30.

${ }^{16}$ Wellum, God the Son Incarnate, 70.
} 
kepercayaan yang absolut, rancangan rasional atas strata sosial yang ideal dan standarisasi pengetahuan."17 Sebagai gantinya, pascamodernisme menawarkan koherenisme, universalisme dan pragmatisme yang menekankan bahwa nilai rasional terhadap sesuatu tidak bersifat universal namun bersifat kontekstual dan relatif, sesuai dengan kesepakatan masyarakat tertentu. ${ }^{18}$

Untuk mendukung koherenisme, universalisme dan pragmatisme tersebut, secara radikal, pascamodernisme berusaha mendobrak kaitan antara bahasa dan realitas yang terwujud dalam budaya Barat yang logosentris dan menggantinya dengan kaitan antara bahasa dan budaya. ${ }^{19}$ Menurut Jacques Derrida, there is nothing outside the text, artinya setiap realitas dibungkus dengan bahasa yang mempunyai arti sesuai dengan kesepakatan sosial. ${ }^{20}$ Dengan demikian, segala sesuatu dinilai berdasarkan perspektif tertentu saja dan tidak ada kebenaran, kenyataan atau kebaikan melainkan semuanya itu hanya masalah interpretasi. $^{21}$

Dalam perspektif Jean-Francois Lyotard, era pascamodern merupakan era dengan kondisi hilangnya narasi besar dari budaya yang disebabkan ketidakmampuan masyarakat pascamodern untuk melihat berbagai fenomena dalam konteks yang lebih menyeluruh. $^{22}$ Selain itu, pascamodernisme meledakkan mitos tentang innocent eyes dalam melihat tiga hal penting dalam hidup manusia yaitu Tuhan, dunia dan diri manusia sendiri. ${ }^{23}$ Menurut pandangan pascamodern, tidak ada

${ }^{17}$ David Harvey, The Condition of Postmodernity (Oxford: Blackwell, 1989), 9.

${ }^{18}$ Wellum, God the Son Incarnate, 70.

${ }^{19}$ Ibid., 70-71.

${ }^{20}$ Jacques Derrida, Of Grammatology (Baltimore: John Hopkins University Press, 1982), 158.

${ }^{21}$ Wellum, God the Son Incarnate, 71.

${ }^{22}$ Ulasan kondisi pascamodern menurut Lyotard ini dapat dilihat dalam "Introduction," The Postmodern Bible Reader, ed. David Jobling, Tina Pippin, and Ronald Schleifer (Malden: Blackwell, 2001), 1-8.

${ }^{23}$ Vanhoozer, First Theology, 19. innocent eyes karena ada agenda-agenda politik dan kepentingan-kepentingan tertentu yang berkaitan dengan kekuasaan di dalam penafsiran sehingga penafsiran tidak bisa bersifat netral.

Di tengah semua perubahan cara pandang yang ditawarkan pascamodernisme, ada satu sisi positif yang sangat membangun dalam era ini. Sisi positif dari pascamodernisme adalah pandangannya yang menyerukan kegiatan altruistik kepada konteks dan epistemologi sosial. $^{24}$ Hal ini membawa kelegaan besar dan sekaligus memberikan gambaran kontras dari situasi yang ada di mana kaum radikal dari sekelompok aliran agama menjadi altruis (orang yang mengutamakan kepentingan orang lain) radikal dalam kepercayaan mereka. ${ }^{25}$

Selain pandangan sosial, pascamodernisme juga mempunyai pandangan yang unik tentang religiusitas. Ini tampak, misalnya, dalam pemahaman terhadap konsep Tuhan atau ketuhanan. Menurut Feinberg, pascamodernisme memaknai keberadaan Tuhan sebagai " $A$ God who is immanent and relational; $a$ God whose very being interpenetrates all things and hence underscores the connectedness of all things; a God who is not static but is constantly changing as he responds to our needs; and a God to whom we can contribute value as well as one who enhances our existence. ${ }^{26}$ Dengan kata lain, pandangan ini mengharapkan adanya relasi yang dekat antara manusia dan Tuhan di mana sang ilahi ini dapat hadir dalam setiap segi kehidupan manusia dan eksistensi manusia dianggap berharga.

Pascamodernisme memunculkan masalah utama dalam kristologi yaitu hal yang berhubungan dengan natur kemanusiaan dan

${ }^{24}$ Edith Wyschogrod, "Saintliness and Some Aporias of Postmodern from Saints and Postmodernism," dalam The Postmodern God: A Theological Reader, ed. Graham Ward (Malden: Blackwell, 1997), 341.

${ }^{25}$ Ibid.

${ }^{26}$ John S. Feinberg, No One Like Him: The Doctrine of God (Wheaton: Crossway, 2001), 142. 
identitas Yesus. ${ }^{27}$ Shult menantang kristologi ortodoks untuk berubah pandangan dari prinsip natur-substansi menjadi evolusi-biologis dalam melihat doktrin inkarnasi. ${ }^{28}$ Menurutnya formulasi ortodoks yang menekankan kaitan antara kemanusiaan Yesus dan natur manusia Adam sebelum kejatuhan harus disingkirkan. ${ }^{29}$

\section{Pendekatan Hermeneutis Redemptive- Historical}

Pada abad pertama, Irenaeus, Athanasius dan beberapa teolog lainnya memberikan respon terhadap ancaman Gnotisisme dan Arianisme dengan menyerukan pembacaan Alkitab sebagai sebuah sejarah penebusan. ${ }^{30}$ Melalui pendekatan ini mereka melihat adanya sebuah alur yang mempunyai kesatuan integral yang merefleksikan kesatuan kanon secara umum. Pendekatan ini terus dikembangkan pada abad enam belas dan tujuh belas dan kemudian diikuti oleh Jürgen Moltmann pada abad dua puluh yang terus mengumandangkan teologi sejarah penebusan yang alkitabiah. ${ }^{31}$ Dengan memperbarui fokus pembacaan Alkitab kepada kesatuan teks seputar Kristus dan penebusan seperti yang dilakukan dalam pendekatan tersebut, maka muncul ketertarikan tentang sejarah penebusan dan pewahyuan.

Dalam perjalanannya, meskipun kebangkitan gerakan pietisme dan rasionalisme berusaha menggempur pendekatan ini dalam tataran teologi akademis, namun pendekatan ini terus mendapatkan perhatian sampai abad kedua puluh. $^{32}$ Pendekatan redemptive-historical ini makin berkembang pada era Reformasi dan

${ }^{27}$ Wellum, God the Son Incarnate, 74.

${ }^{28}$ Seperti yang dikutip oleh Wellum, ibid.

${ }^{29}$ Ibid., 74-75.

${ }^{30}$ Michael Horton, Covenant and Eschatology:The Divine Drama (Louisville: Westminster John Knox, 2002), 5.

${ }^{31}$ Bdk. Jürgen Moltmann, "Creation and Redemption," dalam Creation, Christ \& Culture: Studies in Honour of T. F. Torrance, ed. by Richard W.A. McKinney (Edinburgh: T\&T Clark, 1976), 119-134

${ }^{32}$ Horton, Covenant and Eschatology, 5.
post-Reformasi Protestan. ${ }^{33}$ Geerhardus Vos disinyalir sebagai sarjana biblika penggagas awal pendekatan ini, ketika ia mengajar di Princeton Theological Seminary, Amerika Serikat, mulai 1893 hingga ia pensiun pada 1932. ${ }^{34}$ Kesadaran Vos terhadap pentingnya peran sejarah keselamatan dalam penafsiran Alkitab muncul sebagai reaksi atas tradisi akademis dalam studi biblika Protestan yang sangat mendewakan intelek dan rasio.

Untuk menyatakan penolakan terhadap tradisi tersebut, ia menyatakan bahwa Allah tidak tanpa sengaja merangkai wahyu-Nya dalam sebuah buku sejarah dan bukan dalam sistem dogmatika karena Allah ingin menyentuh hati manusia yang terdalam dengan perjalanan sejarah yang nyata. ${ }^{35} \mathrm{Hal}$ ini ia gambarkan sebagai berikut:

It is certainly not without significance that God has embodied the contents of revelation, not in dogmatic system, but in a book of history, the parallel to which in dramatic interest and simple eloquence is nowhere to be found. It is this that makes the Scripture speak and appeal to and touch the hearts and lead the minds of men captive to the truth everywhere. No one will be able to handle the word of God more effectually than he to whom the treasure-chambers of its historic meaning have been opened up. It is this that brings the divine truth so near to us, makes it as it were bone of our bone and flesh of our flesh, that humanizes it in the same sense that the highest revelation in Christ was rendered most human by the incarnation. ${ }^{36}$

Sependapat dengan pernyataan di atas, Lints menyatakan bahwa fakta fundamental dari Alkitab adalah bahwa Alkitab merupakan sebuah teks yang berisi cerita yang berkembang; sebuah cerita yang secara progresif

\footnotetext{
${ }^{33}$ Richard B. Gaffin Jr., "The Redemptive-Historical View," dalam Biblical Hermeneutics: Five Views, ed. Stanley E. Porter and Beth M. Stovell (Downers Grove: IVP Academic, 2012), 89.

${ }^{34}$ Ibid.

${ }^{35}$ Vos, Redemptive History and Biblical Interpretation, 23.

${ }^{36}$ Ibid.
} 
dinyatakan hingga mencapai satu tujuan spesifik yang sudah ditetapkan oleh Sang Pembuat cerita. ${ }^{37}$ Tujuan spesifik tersebut adalah sebuah mahakarya ilahi yang terwujud dalam sebuah karya penebusan (redemption) yang tertuang dengan jelas dalam narasi besar yang dipaparkan dalam Alkitab. Yang dimaksudkan dengan "penebusan" di sini adalah sebuah karya yang disingkapkan oleh Allah dari waktu ke waktu di mana Allah tidak hanya mendesainnya tetapi juga terlibat aktif di dalamnya. Lints menegaskan ini dengan mengatakan:

The "story" of God's involvement with and redemption of his people is acted out on the stage of history with many distinct but related parts. And it is vital to our understanding of this history that we take note of the fact that God acts in and through history. He is not simply the grand professor at the head of the class who stands and lectures. He is integrally involved in human history, serving not only as the author of the "story" of redemption history but also as a genuine character in the story. ${ }^{38}$

\section{Alat-alat Analisis Pendekatan Hermeneutis Redemptive-Historical}

Ada tiga alat analisis yang dapat diterapkan dalam pendekatan redemptive-historical ini yaitu revelation (pewahyuan), eschatology (eskatologi) dan tipology (tipologi). Berkaitan dengan pewahyuan, pewahyuan adalah produk dari penebusan dalam sejarah di mana kedua hal ini saling terhubung dengan erat. Menurut Vos, hubungan tersebut dicirikannya dengan empat hal: "the historic progressiveness; the actual embodiment in history; the organic nature of the historic process observable in revelation; practical adaptability." 39 Lebih lanjut, ia menjelaskan peran pewahyuan sebagai berikut:

${ }^{37}$ Richard Lints, The Fabric of Theology: A Prolegomenon to Evangelical Theology (Grand Rapids: Eerdmans, 1993), 262.

\footnotetext{
${ }^{38}$ Ibid., 262-263.

${ }^{39}$ Geerhardus Vos, Biblical Theology: Old and New Testament (Carlisle: The Banner of Truth Trust, 1975), 5-7.
}

By "redemptive-historical," then is meant the organic unfolding of the divine plan in its execution through word (announcement), act (accomplishment) and word (interpretation). Revelation is therefore the servant of redemption, circumventing any conception of revelation as mere enlightment, gnosis, information, or full presence. ${ }^{40}$

Senada dengan Vos, Poythress melihat kaitan yang erat antara pewahyuan sebagai perkataan Allah dan penebusan sebagai tindakan Allah. Dari pernyataan Allah akan kedua hal tersebut, didapatkan lima pemahaman penting. ${ }^{41}$ Pertama, Allah tidak menyatakan segala sesuatu dalam sekali waktu namun secara berkesinambungan. Kedua, pernyataan Allah yang selanjutnya akan menerangi pernyataan Allah yang sebelumnya. Ketiga, pernyataan Allah yang berikutnya merupakan penggenapan dari pernyataan terdahulu yang dengan demikian umat-Nya akan memperoleh pengertian yang lebih dalam. Keempat, tindakan Allah dimaksudkan untuk memperjelas firman-Nya, demikian juga sebaliknya. Kelima, setiap perbuatan dan perkataan Allah ditujukan dalam konteks tertentu dalam tahapan tertentu sebagai bagian dari rangkaian sejarah keselamatan yang puncaknya terletak dalam karya Yesus dan penyempurnaannya terwujud pada hadirnya langit dan bumi yang baru.

Alat analisis kedua adalah eskatologi. Eskatologi harusnya menjadi sebuah lensa dan bukan hanya sebuah lokus dalam perjalanan teologi biblika karena eskatologi ini mempunyai pengaruh yang besar terhadap cara pandang teologi dalam studi Kitab Suci. ${ }^{42}$ Jantung dari pemahaman teologi sebagai eskatologi adalah dialektika the already but not yet. ${ }^{43} \mathrm{Hal}$ ini berarti bahwa aspek eskatologis tidak berbentuk garis lurus yang horisontal melainkan

\footnotetext{
${ }^{40}$ Horton, Covenant and Eschatology, 5.

${ }^{41}$ Vern S. Poythress, Reading the Word of God in the Presence of God: A Handbook for Biblical Interpretation (Wheaton: Crossway, 2016), 226.

${ }^{42}$ Horton, Covenant and Eschatology, 5.

${ }^{43}$ Ibid.
} 
berbentuk jalinan-jalinan yang terjalin antara unsur vertikal (ilahi) dengan sejarah manusia di mana alur tersebut dinyatakan melalui letupan-letupan apokaliptis yang berkait dengan perjalanan sejarah bangsa Israel secara khusus hingga masa yang akan datang.

Alat analisis yang ketiga dalam menghadirkan pendekatan redemptive-historical adalah dengan tipologi. ${ }^{44}$ Tipologi berbeda dari alegori dan hal ini seperti apa yang dinyatakan oleh Wellum sebagai berikut:

The major difference between typology and allegory is that typology is grounded inauthorial intent. Typology looks to the text for an intertextual development of historical persons, events and institutions intended by God to correspond to each other; allegory does not assume this. Also, since allegories are not grounded inauthorial intent that is (inter)textually warranted, allegorical interpretation depends on some kind of extratextual grid to warrant its explanation. ${ }^{45}$

Dengan kata lain, perbedaan yang paling signifikan antara tipologi dan alegori adalah pertaliannya dengan maksud dari penulis teks di mana makna teks tipologi dapat dilacak dari pengembangan teks pada bagian lainnya (intertekstual) sedangkan penafsiran alegori sangat bergantung pada hal-hal di luar teks untuk membuktikan kebenarannya (ekstratekstual). Senada dengan Wellum, Lints menjelaskan bahwa tipologi secara sederhana dapat diartikan sebagai sebuah simbolisme yang rujukannya bakal digenapi pada zaman yang akan datang dalam sejarah alkitabiah. ${ }^{46}$ Lebih lanjut ia menjelaskan bahwa tipologi melibatkan hubungan organis yang fundamental antara peristiwa, orang dan institusi di suatu zaman yang disebut "tipe", dan penggenapannya di zaman berikutnya yang disebut "antitipe." ${ }^{47}$ Penafsiran seperti ini membawa kepada sebuah pengertian yang

\footnotetext{
${ }^{44}$ Lints, The Fabric of Theology, 304.

${ }^{45}$ Wellum, God the Son Incarnate, 98.

${ }^{46}$ Lints, The Fabric of Theology, 304.

${ }^{47}$ Ibid.
}

mendalam akan simbol dari konteks aslinya yang kemudian mengarahkan kepada pengharapan eskatologis yang akan terpenuhi di masa yang akan datang. ${ }^{48}$

\section{Horison-horison Pendekatan Hermeneutis Redemptive-Historical}

Dalam mengembangkan ketiga alat analisis di atas, Lints menawarkan tiga horison sebagai perspektif dasar di dalam membaca teks Alkitab, yaitu textual horizon, epochal horizon dan canonical horizon di mana ketiga horison ini diikat dalam satu benang merah sejarah keselamatan atau penebusan (redemptive history). ${ }^{49}$

\section{Horison Teks (The Textual Horizon)}

Secara sederhana teks memang dapat dipahami berdasarkan apa yang dikatakan teks itu sendiri namun pembacaan dengan cara ini dapat menghasilkan penafsiran yang terlalu sempit dan subjektif. Karena itu, diperlukan suatu biblical framework yang mumpuni untuk mendapatkan analisis teologis yang benar dari sebuah teks Alkitab. Tentu saja hal ini bukanlah pekerjaan mudah untuk dilakukan karena natur kepenulisan dari teks Alkitab sendiri bersifat ganda di mana terdapat human author(s) dan juga divine author. Kendati demikian, landasan utama dalam melihat teks Alkitab adalah pemahaman bahwa seluruh isi Alkitab, dari Perjanjian Lama hingga Perjanjian Baru, adalah wahyu Allah yang menyatakan adanya keselamatan di dalam diri dan karya Yesus Kristus.

Selain itu, horison teks ini mengingatkan bahwa keragaman bentuk teks dalam Alkitab juga menuntut metode penafsiran yang lebih kompleks yang sering kali melibatkan berbagai unsur penafsiran secara luas. Simbolisme, perumpamaan, genre, gramatika, konteks historis, dalam teks Alkitab harus dikaji dengan saksama untuk mendapatkan makna yang tepat. Berkaitan dengan simbol dan

\footnotetext{
${ }^{48}$ Ibid., 309.

${ }^{49}$ Horison-horison ini keseluruhan diadaptasi dari pemikiran Lints. Lih. ibid., 293-309.
} 
perumpamaan, Lints mengingatkan bahwa simbol dan perumpamaan di dalam teks tidak dapat diterjemahkan secara harfiah karena penafsir harus memperhatikan kerangka teologis dan konteks yang dibangun oleh penulis teks. Selain itu, aspek gramatika dan konteks historis juga menjadi perhatian penting dalam penafsiran yang objektif karena hal itu memberikan telaah yang lebih rinci atas kata per kata yang dibatasi oleh konteks historis tertentu sehingga makna yang dimaksudkan dalam teks menjadi lebih jelas. Berkaitan dengan penulisan, kemajemukan gaya sastra penulisan juga membuat penafsiran mempunyai unsur multi-dimensi dalam penggaliannya.

\section{Horison Zaman (The Epochal Horizon)}

Tuhan menyatakan wahyu penebusan kepada manusia secara progresif dalam tahapantahapan, melalui zaman ke zaman berikutnya yang terjalin dalam sejarah umat manusia. Istilah "epoch" di sini mengacu kepada setiap zaman yang mempunyai kekhususannya tersendiri di dalam memahami Allah sesuai dengan bagian yang dinyatakan Allah sendiri kepada orang-orang pada zaman tertentu. Hal ini tidak serta-merta berarti bahwa Allah dan janji-Nya terus berubah-ubah dari zaman ke zaman. Sebaliknya, justru pernyataan Allah yang progresif ini memunculkan sisi-sisi diri-Nya yang unik dan berlainan pada setiap masa yang berbeda.

Penekanan horison ini ada pada cara melihat kesatuan dari zaman ke zaman dalam kerangka besar rencana keselamatan umat manusia yang dirancangkan Allah dari semula. Karena itu, penafsiran Alkitab harus memperhatikan signifikansi dari tiap era dan menemukan tema sentral yang dinyatakan pada zaman itu dan beberapa isu lainnya yang berkaitan dengan zaman tersebut, seperti yang Lints katakan:

In addition to marking the significant epochs, we should devote some care and attention to isolating the central themes and concerns of each epoch. What are the central covenantal terms of the period? What are the particular intentions of the author (s) in that epoch? Why are certain issue repeated time and again in particular periods? How do the central themes of one epoch relate to the central themes of another epoch $?^{50}$

Hal ini sekaligus mengingatkan bahwa akan ada kesulitan yang mungkin timbul dalam aplikasi dari horison zaman ini, khususnya ketika mengaitkan kitab-kitab tertentu yang tidak secara langsung berhubungan atau terkait dengan sejarah penebusan seperti kitabkitab hikmat. Kendati demikian, untuk melihat peran kitab-kitab tersebut dalam satu rangkaian sejarah keselamatan diperlukan horison kanon yang dapat menjelaskan kesinambungan antarkitab secara khusus.

\section{Horison Kanon (The Canonical Horizon)}

Hal yang paling pokok dalam horison kanon yang berkaitan dengan penafsiran alkitabiah adalah kesinambungan antara janji Allah dan pemenuhannya. Horison ini berfungsi sebagai penyatu setiap zaman yang tertulis dalam bagian-bagian Alkitab. Model janjipenggenapan (promise-fulfillment) merupakan benang merah yang menyambungkan rangkaian teks yang bervariasi menjadi satu kesatuan yang menawarkan makna teks yang sesuai dengan konteks dan juga pengharapan akan masa depan. Pengharapan ini tentu saja menuntut adanya iman dalam penggenapannya. Karena itu, Childs mengatakan bahwa kanon tidak hanya berbicara mengenai bentuk literatur dan sekumpulan kitab tetapi juga berkaitan erat dengan regula fidei dari gereja mula-mula sebagai sebuah komunitas. ${ }^{51}$

Untuk menumbuhkan regula fidei tersebut, khususnya dalam melihat Alkitab sebagai sebuah kanon, Wall menekankan lima hal

\footnotetext{
${ }^{50}$ Ibid., 303.

${ }^{51}$ Seperti yang dikutip oleh Peter Ben Smit dalam "Canonical Exegesis of the New Testament Gospels: Five Cases," From Canonical Exegesis to Ecumenical Exegesis: A Study in Biblical Hermeneutics, ed. Eddy Van der Borght, vol. 30, Studies in Reformed Theology (Leiden: Brill, 2015), 22.
} 
penting yang harus diperhatikan. ${ }^{52}$ Pertama, Alkitab harus didekati sebagai sebuah teks manusia di mana pendekatan ini mengakui adanya peran manusia dan natur sejarah dari teks Alkitab. Kedua, Alkitab dianalisis sebagai sebuah teks yang sakral. Maksudnya, ada inspirasi dari Roh Kudus di dalam penulisan dan penyusunan firman Allah bahkan juga dalam pemeliharaannya dari zaman ke zaman sehingga pada akhirnya berbentuk satu kumpulan kitab seperti sekarang ini. Ketiga, Alkitab didekati sebagai sebuah teks tunggal dalam arti sebagai suatu kesatuan di mana bagian-bagian di dalamnya saling menerangi satu dengan yang lain. Ada semacam percakapan intrakanonikal, seperti yang Wall kemukakan:

Recognizing that the single biblical canon was formed under the direction of one God for the edification of one church creates a new context in which the texts of diverse witnesses are read together, one text iluminating the fuller meaning of another. In addition to the antecedent canonical texts alluded to or quoted by biblical writers, the linguistic and thematic connections between texts within the Christian biblical canon create "intracanonical conversations" that iluminate the theological understanding of faithful readers. ${ }^{53}$

Keempat, Alkitab didekati sebagai sebuah teks yang terbentuk dengan maksud tertentu (shaped text). Maksudnya, ini adalah sebuah proses kanonisasi yang melibatkan pengumpulan berbagai tulisan individu disusun secara koheren untuk memenuhi satu tujuan tertentu. Penyusunan tersebut mengindikasikan bahwa tiap koleksinya didesain untuk satu peran tertentu dalam kesatuan Alkitab dan terhubung dengan bagian lainnya secara unik. Kelima, terakhir, Alkitab dilihat sebagai sebuah teks gereja. Hal ini berarti peran gereja sebagai komunitas orang beriman

\footnotetext{
${ }^{52}$ Robert W. Wall, "The Canonical View," dalam Biblical Hermeneutics: Five Views (Downers Grove: IVP Academic, 2012), 112-113.

${ }^{53}$ Ibid., 117.
}

sangat penting dalam keseluruhan proses penafsiran.

Menekankan bagian yang terakhir dari kelima hal di atas, penafsiran yang melibatkan peran jemaat gereja sebagai tubuh Kristus dapat menghindarkan dari penafsiran yang tidak sehat. Wall menegaskan hal ini demikian:

Not only do various Bible practices find their home in a congregational setting and their purpose in aiming believers at God, but also it is in the company of the saints that the spiritual authority of the biblical interpreter is honed and confirmed. Along with intelectual equipment required to work with biblical texts skillfully, the virtues necessary to read sacred texts after the mind of Christ are also formed within the body of Christ. The congregation encourage the self-awarness and maturity of one who can avoid sinful tendencies in interpretating biblical texts. ${ }^{54}$

Keterlibatan jemaat Tuhan secara luas dalam proses penafsiran sangat diperlukan karena penafsiran sudah seharusnya lahir dari gereja sebagai kesatuan tubuh Kristus. Kesadaran akan pentingnya keterlibatan tubuh Kristus dalam penafsiran dapat menghindarkan jemaat dari penafsiran yang tidak sesuai dengan kebenaran Alkitab, dan menjadikan mereka semakin terdidik dan tepat dalam memahami Kitab Suci.

\section{Pendekatan Hermeneutis Redemptive- Historical Menjawab Permasalahan Kristologis Modern dan Pascamodern}

\section{Pendekatan Hermeneutis Redemptive- Historical dan Modernisme}

Tanggapan pertama diarahkan kepada soal epistemologi modern yang menghasilkan kristologi kritis. Penulis berpendapat bahwa tekstual horison dapat menjadi jembatan penghubung bagi peradaban modern yang mendekati teks secara analitis. Objektivitas penafsiran dalam horison tekstual ini sangat teruji karena penafsiran dilakukan dengan perangkat literaris modern yang dapat dipahami

\footnotetext{
${ }^{54}$ Ibid., 121.
} 
dengan jelas. ${ }^{55}$ Selain itu, aspek gramatika dan konteks historis di mana teks itu berada akan menjadi penekanan dalam horison tekstual ini. Horison ini bukan saja mendukung rasionalitas dari zaman modern tetapi juga tidak mengabaikan kerangka besar yang lebih penting, yaitu penebusan, dalam pembacaan Alkitab.

Selanjutnya, dalam hal terjadinya terjadinya perpisahan yang besar akibat metode penafsiran objektif-kritis di era modern, penulis menemukan satu penyelesaian sederhana di dalam pendekatan redemptive-historical ini. Perpisahan besar antara gereja dan akademi, devosional dan intelektual, iman dan akal budi yang dipaparkan olehnya dapat didekati dengan aspek horison kanonikal yang merupakan salah satu alat dalam pendekatan ini. Salah satu hal yang ditekankan dalam horison kanon ini adalah bahwa Alkitab harus dilihat sebagai teks gereja di mana hal ini berarti bahwa gereja sebagai komunitas orang percaya dapat terlibat aktif dalam penafsiran Alkitab. ${ }^{56}$ Dengan demikian, penafsiran Alkitab tidak menjadi monopoli dari kaum intelektual dan akademisi saja. Hal ini akan menangkal terjadinya great divorce antara gereja dan akademi; devosional dan intelektual; iman dan akal budi.

Akhirnya, mengenai ketergantungan doktrin kristologi pada hasil penelitian sejarah memang patut ditanggapi dengan serius. Ketegangan yang timbul akibat rekonstruksi sejarah Yesus dengan aspek doktrinal dari kristologi memang tidak dapat dihindari. Meskipun demikian, melalui pendekatan redemptive-historical ini, ketegangan yang ada dapat diminimalkan. Wall menegaskan bahwa, ketika Alkitab dilihat sebagai sebuah kanon, itu berarti Alkitab dilihat sebagai karya manusia sekaligus karya Allah sendiri di mana Roh Kudus memberikan inspirasi kepada para penulisnya. ${ }^{57} \mathrm{Hal}$ ini berarti, ketika pembuktian sejarah tidak menunjukkan kebenaran

${ }^{55}$ Lih. Lints, The Fabric of Theology, 295-300.

${ }^{56}$ Lih. Wall, “The Canonical View," 121.

${ }^{57}$ Ibid., 114-116. seperti yang dinyatakan dalam Alkitab, maka kebenaran yang diterima adalah kebenaran yang berdasarkan Alkitab karena pembacanya mengakui otoritas Alkitab yang diinspirasikan oleh Allah sendiri. Jadi dalam hal ini, doktrin kristologi tidak bergantung sepenuhnya pada hasil penemuan-penemuan historis yang diupayakan oleh para sarjana biblika modern.

\section{Pendekatan Redemptive-Historical dan Pascamodernisme}

Seperti telah diulas sebelumnya, pascamodernisme melihat hidup ini sebagai kumpulan cerita di mana tiap individu mempunyai cerita dan cerita-cerita itu bisa saling terhubung antara satu dengan yang lainnya. Keterhubungan ini pada akhirnya dapat mengarahkan pandangan pascamodern untuk melihat bahwa subyektivitas, bias personal dan sudut pandang yang terbatas dari tiap individu telah menghalangi untuk melihat satu gambar besar yang sedang dikerjakan oleh Allah dalam kehidupan ini. Dengan menerapkan aspek horison zaman yang ditawarkan pendekatan redemptive-historical, penyangkalan pascamodern terhadap metanaratif ini dapat dipatahkan karena horison ini dapat melihat perjalanan sejarah keselamatan yang sudah dikerjakan oleh Allah dari waktu ke waktu, melintasi satu zaman kepada zaman lainnya. ${ }^{58}$ Dengan demikian, kehidupan manusia tidak hanya berhenti dalam tataran individu tetapi juga ada jalinan antara masing-masing individu dari zaman ke zaman yang membentuk suatu gambar besar yang sedang dikerjakan oleh Allah sendiri.

Lalu, berkaitan dengan soal ekspektasi para pascamodernis tentang kehadiran Allah yang relasional, penulis berpendapat bahwa dengan pendekatan ini, masyarakat pascamodern juga dapat lebih merasakan kehadiran Allah dalam sejarah secara nyata sehingga kristologi yang relasional dapat dengan mudah dipahami oleh mereka. Pernyataan Allah yang bertahap atau progresif dari waktu ke waktu merupakan rangkaian

${ }^{58}$ Lih. Lints, The Fabric of Theology, 300-303. 
relasional yang dirancangkan Allah untuk menjalin hubungan dengan manusia. Sebagai puncak pernyataan-Nya, Allah berinkarnasi sebagai manusia dalam diri anak tunggal-Nya, Yesus Kristus, dan bahkan mengambil bagian dalam kelemahan manusia. Ia adalah Allah yang imanen, dekat dan dapat merasakan pergumulan manusia.

Senada dengan pernyataan di atas, seorang pemikir Kristen pascamodern, Michel de Certeau mengatakan bahwa kekristenan adalah sebuah relasi dengan masa lalu yaitu peristiwa tentang Yesus Kristus di mana Yesus disebutkan sebagai suatu archè yang tidak dapat dibungkus dalam obyektivitas pengetahuan tetapi dapat dirasakan dampak kehadiran-Nya dalam komunitas orang percaya. ${ }^{59}$ Dengan demikian, melalui kehadiran Kristus, sejarah yang dinyatakan dalam Alkitab menunjukkan bahwa Allah adalah Allah yang mau berelasi dengan ciptaan-Nya.

Kemudian, dalam pandangan pascamodern yang eksistensialis, segala sesuatu yang berkaitan dengan sejarah hanya signifikan bila berhubungan dengan eksistensi individual. ${ }^{60}$ Demikian pula benar dengan keterkaitan sejarah keselamatan. Keselamatan yang ditawarkan secara universal pada akhirnya menuntut hubungan dan pengakuan individual. Pendekatan redemptive-historical memunculkan pengakuan terhadap peranan tiap individu dengan jelas. Hal ini tergambar melalui bagaimana Allah menyatakan perjanjian-Nya kepada individu-individu yang Ia pilih secara khusus seperti Adam, Nuh, Abraham, Musa dan Daud. Perjanjian ini terus bergulir dari waktu ke waktu dengan berlandaskan pada kesetian-Nya sendiri terhadap tiap individu pilihan-Nya. ${ }^{61}$ Klimaks pemenuhan janji-

${ }^{59}$ Lih. penjelasan Frederick Bauerschmidt, dalam "Michel de Certeau (1925-1986): Introduction," dalam The Postmodern God: A Theological Reader, ed. Graham Ward, Blackwell Reading in Modern Theology (Malden: Blackwell, 1997), 137.

${ }^{60}$ Yung Hoon Hyun, Redemptive-Historical Hermeneutics and Homiletics: Debates in Holland, America and Korea from 1930-2012 (Eugene, OR: Wipf \& Stock, 2015), 63.

${ }^{61}$ Lih. Lints, The Fabric of Theology, 301.
Nya akhirnya tergenapi dalam diri Yesus Kristus yang menjadi jalan keselamatan bagi tiap individu yang percaya dalam nama-Nya. Allah tidak hanya bekerja sampai tergenapinya karya keselamatan di atas kalvari, tetapi juga terus bekerja dalam sejarah keselamatan hingga masa kini untuk membawa tiap individu yang percaya kepada Kristus dan kepada penggenapan perjanjian di dalam diri-Nya.

Persoalan terakhir yang lahir dari era pascamodernisme adalah munculnya kelompok injili pascakonservatif (post-conservative evangelicals). ${ }^{62}$ Maksud kemunculan kelompok ini adalah untuk menurunkan ketegangan antara kekristenan dengan pandangan pascamodern. Kehadirannya yang jauh dari kesan bermusuhan, membawa dampak yang baik bagi relasi kekristenan dengan zaman. Pendekatan redemptive-historical dapat mengakomodasi pandangan golongan ini dalam tiga hal: ortodoksi yang ramah namun kritis, pendekatan dialogis, dan pandangan yang relational terhadap Allah. Kemudian, berkenaan dengan kebenaran, ada beberapa hal yang harus diwaspadai dari sikap pascakonservatif injili ini, misalnya, sikap inklusif mengenai keselamatan. Menanggapi hal ini, pendekatan ini tidak dapat mendukung posisi inklusivitas yang diajukan oleh kelompok pascakonservatif ini karena penafsiran dengan pendekatan ini akan selalu bersifat kristosentris. Penyingkapan progresif yang dinyatakan Allah dari waktu ke waktu tetap bermuara pada sosok sentral dari sejarah keselamatan yaitu Yesus Kristus. ${ }^{63}$

\section{Kesimpulan}

Pendekatan hermeneutis redemptive-historical dapat menjadi salah satu pendekatan hermeneutis yang cukup menjawab pergumulan kristologi di era modern. Sifat analitis dari pandangan modern yang melahirkan kristologi kritis dapat diseimbangkan dengan pendekatan ini karena pendekatan ini pun

\footnotetext{
${ }^{62}$ Grant Osborne, Hermeneutical Spiral: A Comprehensive Introduction to Biblical Interpretation (Downers Grove: InterVarsity, 2006), 402.

${ }^{63}$ Lih. Lints, The Fabric of Theology, 301.
} 
mengakomodasi pandangan modern dalam aspek horison tekstual khususnya. Selain itu, keterpisahan aspek intelektual dan devosional yang lahir di era modern juga dapat diatasi dengan pendekatan yang melibatkan komunitas gereja sebagai penafsir ini. Hal lain yang menjadi sumbangsih pendekatan ini, khususnya dalam hal menegakkan kristologi yang alkitabiah, adalah aspek horison kanon. Horison ini yang memandang Alkitab sebagai kitab yang mempunyai unsur kepenulisan ilahi dan manusiawi melepaskan kebergantungan penuh terhadap penelitian ilmiah atas historisitas Yesus terkait dengan kristologi.

Berkaitan dengan era pascamodern, menurut penulis, pendekatan ini juga mampu menjadi jawaban atas kebutuhan yang ada di era ini. Kisah-kisah individu dalam masyarakat pascamodern dapat diikat dan dikaitkan secara langsung dengan rangkaian sejarah penebusan yang terus dikerjakan oleh Allah sampai masa sekarang ini. Kebutuhan akan hadirnya Allah yang relasional juga terpenuhi dengan pendekatan redemptive-historical yang menawarkan pembacaan Alkitab yang kristosentris sehingga selalu mengarah pada sosok Allah yang mau berelasi dengan manusia di dalam dan melalui diri Yesus.

Akhirnya, pendekatan hermeneutis redemptive-historical ini mampu menghadirkan pembacaan dan penafsiran Alkitab yang kristosentris, baik dari sudut pandang era modern maupun pascamodern. Kendati demikian, sebagai otokritik untuk tulisan ini sendiri, penulis mengakui bahwa tidak semua tuntutan dari modernisme dapat tertampung dalam pendekatan ini, contohnya, usulan Reimarus dan Lessing yang menghendaki Alkitab diperlakukan sebagai dokumen sejarah tidak dapat dipenuhi oleh pendekatan ini. Meskipun demikian, sebagian dari ide mereka mengenai pengkajian yang lebih mendalam pada teks tetap dapat dilakukan oleh pendekatan ini dengan menerapkan horison teks secara menyeluruh. Contoh lain permasalahan era pascamodern yang tidak dapat dirangkul dengan pendekatan ini adalah tentang tuntutan adanya konsep keselamatan yang bersifat inklusif dan plural karena, pada dasarnya, konsep keselamatan dalam pendekatan yang kristosentris ini selalu bersifat partikular (eksklusif). 


\section{Daftar Kepustakaan}

Bauerschmidt, Frederick Christian. "Michel de Certeau (1925-1986): Introduction." Dalam The Postmodern God: A Theological Reader, diedit oleh Graham Ward. Blackwell, 135-142. Reading in Modern Theology. Malden: Blackwell, 1997.

Derrida, Jacques. Of Grammatology. Baltimore: John Hopkins University Press, 1982.

Drilling, Peter. Premodern Faith in a Postmodern Culture. New York: Rowman \& Littlefield, 2006.

Feinberg, John S. No One Like Him: The Doctrine of God. Wheaton: Crossway, 2001.

Gaffin Jr., Richard B. "The Redemptive-Historical View." Dalam Biblical Hermeneutics: Five Views, diedit oleh Stanley E. Porter and Beth M. Stovell, 89-110. Downers Grove: IVP Academic, 2012.

Haight, Roger. The Future of Christology. New York: Continuum, 2005.

Harvey, David. The Condition of Postmodernity. Oxford: Blackwell, 1989.

Horton, Michael. Covenant and Eschatology: The Divine Drama. Louisville: Westminster John Knox, 2002.

Hyun, Yung Hoon. Redemptive-Historical Hermeneutics and Homiletics: Debates in Holland, America and Korea from 1930-2012. Eugene: Wipf \& Stock, 2015.

Jobling, David, Tina Pippin, and Ronald Schleifer, eds. The Postmodern Bible Reader. Malden: Blackwell, 2001.

Lewis, C.S. God in the Dock: Essay on Theology and Ethics. Diedit oleh Walter Hooper. Grand Rapids: Eerdmans, 1977.

Lints, Richard. The Fabric of Theology: A Prolegomenon to Evangelical Theology. Grand Rapids: Eerdmans, 1993.

Moltmann, Jürgen. "Creation and Redemption." Dalam Creation, Christ \& Culture: Studies in Honour of T. F. Torrance, diedit oleh Richard W.A. McKinney, 119-134. Edinburgh: T\&T Clark, 1976.

Osborne, Grant R. Hermeneutical Spiral: A Comprehensive Introduction to Biblical Interpretation. Downers Grove: InterVarsity, 2006.

Poythress, Vern S. Reading the Word of God in the Presence of God: A Handbook for Biblical Interpretation. Wheaton: Crossway, 2016.

Smit, Peter Ben. "Canonical Exegesis of the New Testament Gospels: Five Cases." Dalam From Canonical Criticism to Ecumenical Exegesis: A Study in Biblical Hermeneutics, diedit oleh Eddy Van der Borght, 19-102. Vol. 30. Studies in Reformed Theology. Leiden: Brill, 2015.

Vanhoozer, Kevin J. First Theology: God, Scripture and Hermeneutics. Downers Grove: IVP Academic, 2002.

. Is There a Meaning in This Text?: The Bible, the Reader and the Morality of Literary Knowledge. Grand Rapids: Zondervan, 1998. 
Vos, Geerhardus. Biblical Theology: Old and New Testament. Carlisle: The Banner of Truth Trust, 1975.

Redemptive History and Biblical Interpretation. Diedit oleh Richard B. Gaffin Jr. Phillipsburg: P\&R, 2001.

Wall, Robert W. "The Canonical View." Dalam Biblical Hermeneutics: Five Views, diedit oleh Stanley E. Porter and Beth M. Stovell, 111-130. Downers Grove: IVP Academic, 2012.

Wellum, Stephen J. God the Son Incarnate: The Doctrine of Christ. Wheaton: Crossway, 2016.

Wyschogrod, Edith. "Saintliness and Some Aporias of Postmodern from Saints and Postmodernism." Dalam The Postmodern God: A Theological Reader, diedit oleh Graham Ward, 341-355. Malden: Blackwell, 1997. 